\title{
Electrospray Tandem Mass Spectrometric Investigations of Morphinans
}

\author{
Klaus Raith and Reinhard Neubert \\ Institute of Pharmaceutics and Biopharmaceutics, Martin Luther University, Halle, Germany
}

Chotima Poeaknapo, Christian Boettcher, and Meinhart H. Zenk

Biocenter, Martin Luther University, Halle, Germany

Jürgen Schmidt

Leibniz Institute of Plant Biochemistry, Halle, Germany

\begin{abstract}
In this study positive ESI tandem mass spectra of the $[\mathrm{M}+\mathrm{H}]^{+}$ions of morphinan alkaloids obtained using an ion trap MS were compared with those from a triple quadrupole MS. This allows to assess the differences of the tandem-in-time versus the tandem-in-space principle, often hampering the development of ESI MS/MS libraries. Fragmentation pathways and possible fragment ion structures were discussed. In order to obtain elemental composition, accurate mass measurements were performed. According to the MS/MS fragmentation pathway, the investigated compounds can be grouped into 4 subsets: (1) morphine and codeine, (2) morphinone, codeinone, and neopinone, (3) thebaine and oripavine, (4) salutaridine and salutaridinol. Salutaridinol-7-O-acetate shows a different fragmentation behavior because of the favored loss of acetic acid. Although most fragment ions occur in both ion trap and triple quad tandem mass spectra, some are exclusively seen in either type. For triple quad, quadrupole time-of-flight and FT-ICR MS/MS, the base peak of morphine results from an ion at $m / z 165$ that contains neither nitrogen nor oxygen. This ion is not found in ion trap MS/MS, but in subsequential MS $^{3}$ and MS ${ }^{4}$. (J Am Soc Mass Spectrom 2003, 14, 1262-1269) (c) 2003 American Society for Mass Spectrometry
\end{abstract}

$\mathrm{D}$ espite the importance of morphine and its biosynthetic relatives, the literature dealing with electrospray ionization mass spectrometry is limited. A number of studies reported on identification and quantification of morphine and related metabolites in biological samples by flowinjection ESI-MS [1], LC/ESI-MS [1-7] or CE/ESI-MS $[8,9]$, mostly from a forensic point of view. Frequently fragmentation by CID is described and applied as LC/MS/MS. Two reviews highlight the field $[10,11]$. Some systematic approaches to the setup of libraries have been undertaken, including data for morphine and codeine [12-14]. However, none of these studies compared data of ion trap and triple quad systems. Most of the morphinan type substances have been investigated before by electron impact ionization MS [15-17]. Tandem MS instrumentation and the principles of operation have been extensively discussed in the literature [18]. In contrast

Published online August 30, 2003

Address reprint requests to Dr. K. Raith, Department of Pharmacy, Institute of Pharmaceutics and Biopharmaceutics, Martin Luther University HalleWittenberg, Wolfgang Langenbeck Str. 4, 06120 Halle (S), Germany. E-mail: raith@pharmazie.uni-halle.de to magnetic sector instruments, triple quadrupole, quadrupole ion trap, and quadrupole time-of-flight are all considered to perform low collision energy fragmentation. Nevertheless, the obtained tandem mass spectra can look remarkably different. Although the structure elucidation potential of CID was early recognized [19], the setup of ESI-MS/MS libraries was hampered by lacking reproducibility. This article provides comparable ion trap and triple quadrupole MS/MS data of all discussed substances. Accurate mass data of selected morphinans were obtained by quadrupole time-of-flight and FT-ICR mass spectrometry, respectively.

\section{Experimental}

\section{Substances}

Codeine (Merck, Darmstadt, Germany), morphine (Merck) and thebaine (Sanofi Synthelabo, Paris, France) are commercially available. Oripavine was a gift from Professor E. Brockmann-Hanssen, UCSF, USA. All other morphinans were synthesized. 


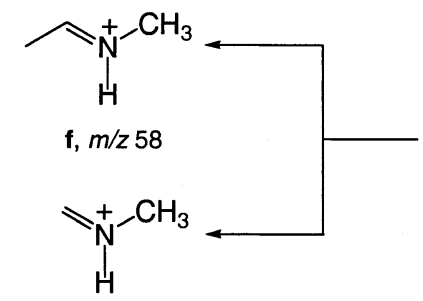

g, $m / z 44$

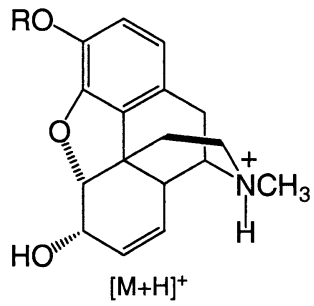

$\mathrm{R}=\mathrm{H}$ (Morphine) $: m / z 286$

$\mathrm{R}=\mathrm{CH}_{3}$ (Codeine) : $\mathrm{m} / \mathrm{z} 300$
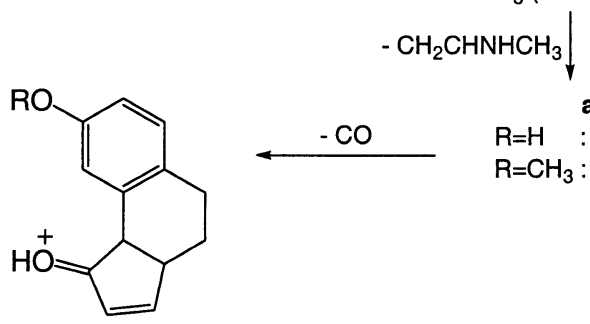

a
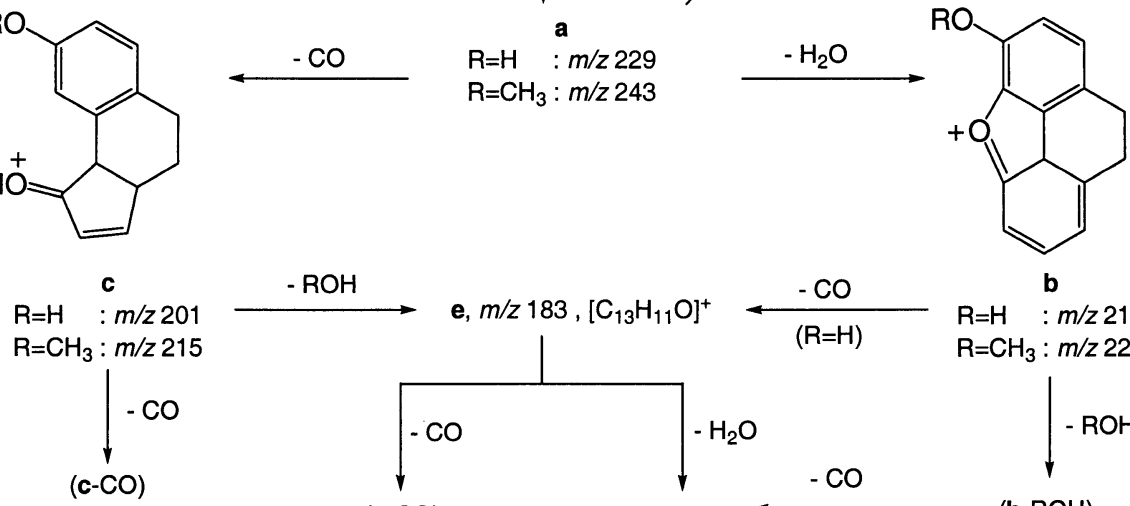

$\mathrm{R}=\mathrm{H} \quad: m / z 173$

$\mathrm{R}=\mathrm{CH}_{3}: m / z 187$

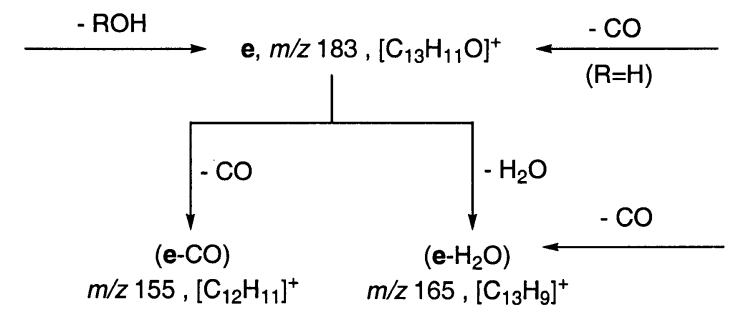

$\mathrm{R}=\mathrm{H} \quad \stackrel{\mathbf{b}}{:} \mathrm{m} / \mathrm{z} 211$

$\mathrm{R}=\mathrm{CH}_{3}: m / z 225$

Scheme 1. Mass spectral fragmentation of the $[\mathrm{M}+\mathrm{H}]^{+}$ions of morphine and codeine.
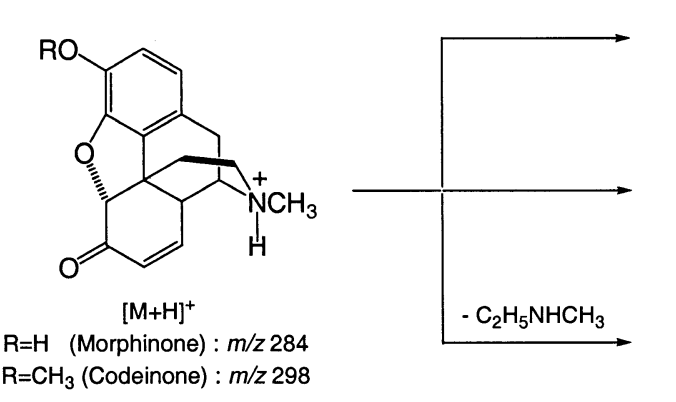

$\widehat{N}_{\mathrm{H}}^{+}-\mathrm{CH}_{3}$

f, $m / z 58$

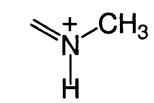

g, $m / z 44$

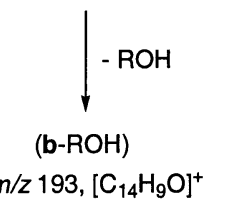

$m / z 193,\left[\mathrm{C}_{14} \mathrm{H}_{9} \mathrm{O}\right]^{+}$

$\mathrm{R}=\mathrm{H} \quad(\mathrm{a}-2 \mathrm{H})$

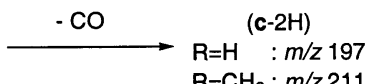

$\mathrm{R}=\mathrm{CH}_{3}: m / z 239$

$\mathrm{R}=\mathrm{CH}_{3}: \mathrm{m} / \mathrm{z} 211$
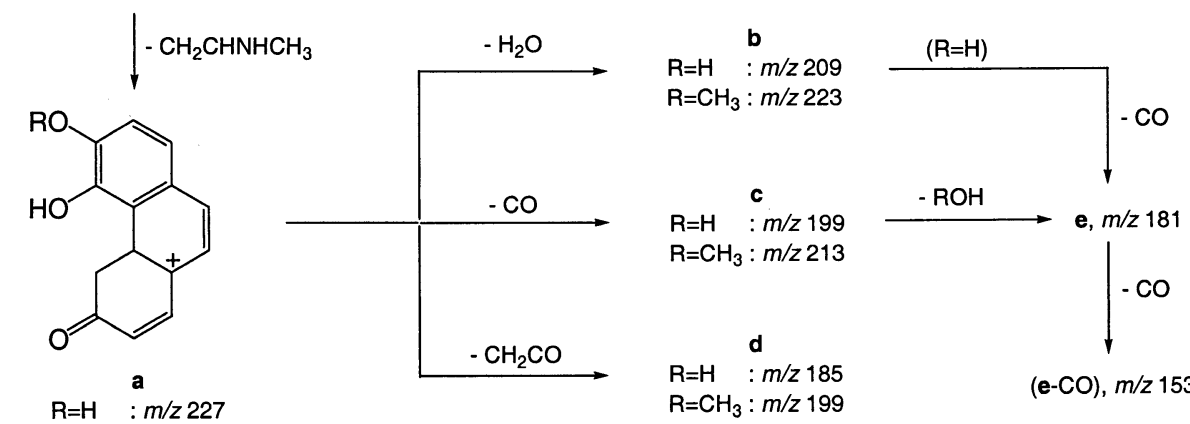

$\mathrm{R}=\mathrm{CH}_{3}: \mathrm{m} / \mathrm{z} 241$

(e-CO), $m / z 153$

Scheme 2. Mass spectral fragmentation of the $[\mathrm{M}+\mathrm{H}]^{+}$ions of morphinone and codeinone. 
Table 1. Key ions in the MS/MS spectra of morphine and codeine. The first row indicates the ions found in the ion trap MS/MS, relative intensity $(\%)$

\begin{tabular}{|c|c|c|c|c|c|c|}
\hline Compound & {$[\mathrm{M}+\mathrm{H}]^{+}$} & a & $(\mathrm{a}-2 \mathrm{H})$ & b & c & $d$ \\
\hline \multirow[t]{2}{*}{ Morphine } & 286 & $229(68)$ & & $211(36)$ & $201(100)$ & $185(10)$ \\
\hline & $286(82)$ & 229 (15) & $227(15)$ & 211 (33) & $201(56)$ & $185(63)$ \\
\hline Codeine & $\begin{array}{c}300 \\
300(100)\end{array}$ & $\begin{array}{l}243(63) \\
243(16)\end{array}$ & $241_{(24)}^{-}$ & $\begin{array}{l}225(34) \\
225(52)\end{array}$ & $\begin{array}{l}215(100) \\
215(60)\end{array}$ & $\begin{array}{l}199(11) \\
199(90)\end{array}$ \\
\hline
\end{tabular}

\section{Mass Spectrometry}

Ion trap MS experiments were performed using a LCQ Classic (ThermoFinnigan, San Jose, CA) equipped with electrospray interface. The spectra shown here are obtained with an ESI voltage of $+4.5 \mathrm{kV}$. In MS/MS and $\mathrm{MS}^{\mathrm{n}}$, the precursor ions were isolated with an isolation width of $2 \mathrm{u}$. As a standardization approach, the collision energy was raised until the relative intensity of the precursor ion dropped to approximately 10\% (achieved at relative collision energies of $15-17 \%$ ).

Triple quadrupole MS experiments were carried out using a TSQ 7000 (ThermoFinnigan, San Jose, CA), equipped with ESI interface (voltage set to $+4.5 \mathrm{kV}$ ). The CID mass spectra were recorded using collision energies of $-20 \mathrm{eV}$ (thebaine, oripavine), $-30 \mathrm{eV}$ (salutaridine, salutaridinol, salutaridinol acetate), and -38 $\mathrm{eV}$ (morphine, morphinone, codeine, codeinone, neopi- none); the collision gas argon was at a pressure of $1.8 \times$ $10^{-3}$ torr.

Quadrupole time-of-flight MS experiments were performed on a Q-Tof 2 (Micromass, Manchester, UK). High resolution ESI-IRMPD (infrared multiphoton dissociation) mass spectra of morphine, codeine, salutaridine, salutaridinol, and salutaridinol acetate were obtained from a BioApex 70e Fourier transform ion cyclotron resonance mass spectrometer (Bruker Daltonics, Billerica, MA) equipped with an Infinity cell, and a 7.0 $\mathrm{T}$ superconducting magnet (Bruker, Karlsruhe, Germany).

\section{Results and Discussion}

The substances under investigation are alkaloids with a basic nitrogen, which makes them predes-

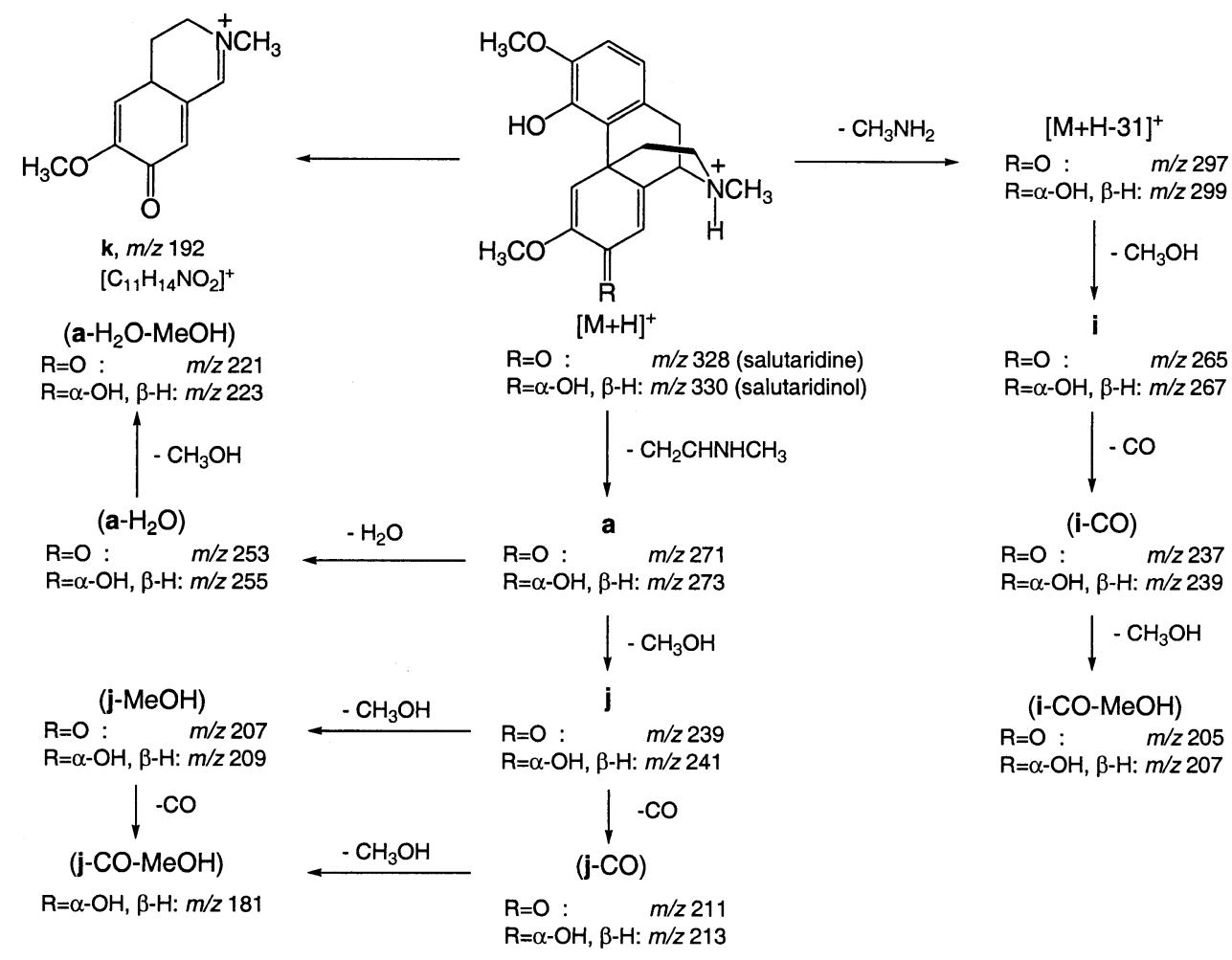

Scheme 3. Mass spectral fragmentation of the $[\mathrm{M}+\mathrm{H}]^{+}$ions of salutaridine and salutaridinol. 
the second row shows those obtained from a triple quadrupole MS/MS (38 eV CID spectra). The values in brackets give the

\begin{tabular}{lcccccl}
\hline $\mathrm{e}$ & $(\mathrm{c}-\mathrm{CO})$ & $\left(\mathrm{e}-\mathrm{H}_{2} \mathrm{O}\right)$ & $(\mathrm{e}-\mathrm{CO})$ & $\mathrm{f}$ & $\mathrm{g}$ & \multicolumn{1}{c}{ Other } \\
\hline \hline $183(18)$ & $173(14)$ & - & $155(5)$ & - & - & $268(26), 239(16), 219(7), 209(8), 193(10), 147(5)$ \\
$183(53)$ & $173(40)$ & $165(100)$ & $155(67)$ & $58(34)$ & $44(31)$ & $209(34), 181(\mathrm{e}-2 \mathrm{H}, 72), 157(\mathrm{~d}-\mathrm{CO}, 63), 153(\mathrm{e}-2 \mathrm{H}-\mathrm{CO}$, \\
& & & & & & $62), 147(29), 145(31), 123(14)$ \\
\hline $183(18)$ & - & - & $155(5)$ & - & - & $282(33), 253(8), 267(6), 175(6), 161(5)$ \\
$183(61)$ & $187(37)$ & $165(98)$ & $155(53)$ & $58(48)$ & $44(32)$ & $\begin{array}{l}266(17), 193(\mathrm{~b}-\mathrm{MeOH}, 31), 171(\mathrm{~d}-\mathrm{CO}, 47), 153(\mathrm{e}-2 \mathrm{H}-\mathrm{CO}, \\
\end{array}$ \\
& & & & $36), 144(21), 137(16)$
\end{tabular}

tined for electrospray ionization (ESI) in positive ion mode. The ESI mass spectra show the $[\mathrm{M}+\mathrm{H}]^{+}$ion throughout (data not shown), which can be detected with high sensitivity $(<1 \mathrm{ng} / \mathrm{mL})$. Without applying CID voltage, no fragments are detected. All compounds have been analyzed by tandem mass spectrometer. Although the CID conditions are largely different for tandem-in-space and tandem-in-time setups, in general the spectra for this class of substances are compara- ble. We have grouped substances showing similar fragmentation behavior in subsets, thus emphasizing the differences between those types.

\section{Morphine and Codeine}

Morphine and codeine show a very similar fragmentation pattern since codeine contains only one additional methyl group (Scheme 1 and Table 1). There-

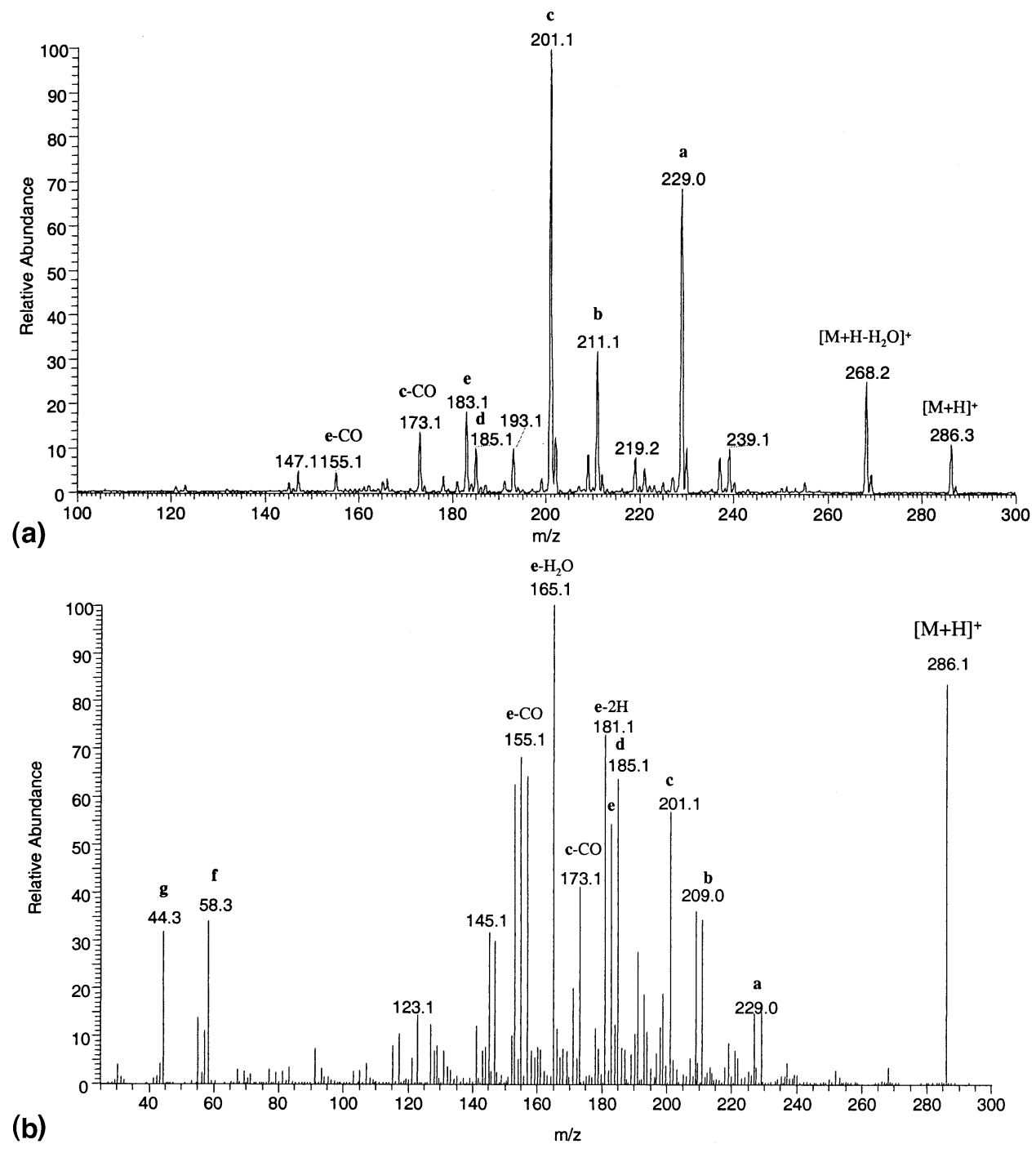

Figure 1. MS/MS of the $[\mathrm{M}+\mathrm{H}]^{+}$ion $[\mathrm{m} / \mathrm{z} 286)$ of morphine (a) ion trap tandem mass spectrum, $\mathrm{MS}^{2}$, (b) $38 \mathrm{eV}$ CID mass spectrum obtained from the TSQ 7000]. 
fore, most fragments found for morphine were also detected for codeine, considering a mass shift by $14 \mathrm{u}$. The $\left[\mathrm{M}+\mathrm{H}-\mathrm{H}_{2} \mathrm{O}\right]^{+}$ion formed by the loss of water from position 6 is only found in the ion trap $\mathrm{MS}^{2}$. The fragments of the type a are formed by cleavage of the piperidine ring and loss of an amine $\left(\mathrm{CH}_{2} \mathrm{CHNHCH}_{3}, \Delta \mathrm{m}=57\right)$. Such a fragment is found for all morphinans and plays a crucial role in further fragmentation pathways (Schemes 1, 2, 3). Fragments of the type $(\mathbf{a}-2 \mathrm{H})$ are not found in case of ion trap but for triple quadrupole MS/MS. Loss of water from ion a leads to the key ion $\mathbf{b}$, expulsion of carbon monoxide to the fragment $\mathbf{c}$. Both pathways come together in the e-type fragment, representing a loss of $\mathrm{CO}$ and water $/ \mathrm{MeOH}$ from the a fragment, respectively. The ion of type $\left(\mathbf{e}-\mathrm{H}_{2} \mathrm{O}\right)$ with the elemental composition of $\left[\mathrm{C}_{13} \mathrm{H}_{9}\right]^{+}$represents the most prominent fragment ion in triple quad, Q-Tof and FT-ICR. The (e-CO) fragment is especially abundant in triple quadrupole MS/MS. Another way leads independently from $[\mathrm{M}+\mathrm{H}]^{+}$to the key ion of type d. Ion trap $\mathrm{MS}^{3}$ of the $[\mathrm{M}+\mathrm{H}-$ $\left.\mathrm{H}_{2} \mathrm{O}\right]^{+}$ion and ion a results in $\mathbf{b}$, whereas fragment c is only formed from a. In case of morphine, $\mathrm{MS}^{3}$ of the base peak at $m / z 201$ (c) gives rise to peaks at $m / z 183(\mathbf{e}, 100), m / z 173(\mathbf{c}-\mathrm{CO}, 18), m / z 165\left(\mathbf{e}-\mathrm{H}_{2} \mathrm{O}, 5\right)$, $\mathrm{m} / \mathrm{z} 155(\mathbf{e}-\mathrm{CO}, 20), \mathrm{m} / \mathrm{z} 145$ (8), and $\mathrm{m} / \mathrm{z} 123$ (10), (relative intensities in brackets). While $\mathrm{MS}^{4}$ of $\mathrm{m} / \mathrm{z}$ 183 (e) results in $m / z 165\left(\mathbf{e}-\mathrm{H}_{2} \mathrm{O}\right)$ and $m / z 155(\mathbf{e}-\mathrm{CO})$, $\mathrm{MS}^{3}$ of $m / z 211(\mathbf{b})$ generates $m / z 193\left(\mathbf{b}-\mathrm{H}_{2} \mathrm{O}\right), m / z 183$ (e), and $m / z 165\left(\mathbf{e}-\mathrm{H}_{2} \mathrm{O}\right) . \mathrm{MS}^{4}$ of $\mathrm{m} / \mathrm{z} 183$ (e) gives $165\left(\mathbf{e}-\mathrm{H}_{2} \mathrm{O}\right)$ and $155(\mathbf{e}-\mathrm{CO})$, indicating that this ion with $\left[\mathrm{C}_{13} \mathrm{H}_{11} \mathrm{O}\right]^{+}$plays a key role in the fragmentation. MS ${ }^{3}$ of $\mathrm{m} / \mathrm{z} 239$ (ion trap only) results in 221 and 193 by consecutive losses of water and CO, respectively. It is noteworthy that some fragments known from triple quadrupole MS/MS such as $\mathrm{m} / \mathrm{z}$ $165\left(\mathbf{e}-\mathrm{H}_{2} \mathrm{O}\right), 145$, and 123 are not present in ion trap MS/MS, but in subsequent $\mathrm{MS}^{3}$ and $\mathrm{MS}^{4}$. The series $\mathrm{m} / \mathrm{z} 239,221$, and 193 seems to be exclusive for the ion trap. Triple quadrupole CID mass spectra display additional key ions at $m / z 58$ (f) and $44(\mathrm{~g})$ representing parts of the piperidine ring. These cannot be detected in ion trap MS/MS, because they are beyond the lower mass range limit, which is set by the instrument software in this case to $\mathrm{m} / \mathrm{z} 75$. Figure 1 shows the tandem mass spectra obtained for morphine using an ion trap (Figure 1a) and a triple quadrupole instrument (Figure 1b). The tandem mass spectra recorded using the Q-Tof and FT-ICR-IRMPD mass spectrometers (data not shown) appear to be similar to the triple quadrupole MS/MS. Both systems are capable of providing accurate mass and thereby elemental composition data, which may aid in the elucidation of fragment structures and routes. In general, ion trap MS/MS shows more high mass fragments than the other techniques. Looking at the ion trap $\mathrm{MS}^{2}$, one can see a water loss fragment at $\mathrm{m} / \mathrm{z} 268$ and another 
Table 3. Key ions in the MS/MS spectra of thebaine and oripavine. The first row indicates the ions found in the ion trap MS/MS, the second row shows those obtained from a triple quadrupole MS/MS (20 eV CID spectra). The values in brackets give the relative intensity $(\%)$

\begin{tabular}{ccccccccrr}
\hline \multicolumn{1}{c}{} & \multicolumn{7}{c}{$[\mathrm{M}+\mathrm{H}-31-[\mathrm{M}+\mathrm{H}-43-$} & \\
Compound $[\mathrm{M}+\mathrm{H}]^{+}$ & {$[\mathrm{M}+\mathrm{H}-31]^{+}[\mathrm{M}+\mathrm{H}-43]^{+}$} & a & $\mathrm{MeOH}]^{+}$ & $\mathrm{MeOH}^{+}$ & (a-MeOH) & $\mathrm{f}$ \\
\hline \hline Thebaine & 312 & $281(100)$ & $269(7)$ & $255(17)$ & $249(56)$ & $237(4)$ & $223(4)$ & - & $280(12), 266(40)$ \\
& $312(66)$ & $281(21)$ & - & $255(8)$ & $249(26)$ & $237(4)$ & $223(5)$ & $58(100) 266(27), 221(7)$ \\
\hline Oripavine & 298 & $267(100)$ & $255(10)$ & $241(10)$ & $249(20)$ & $223(34)$ & - & - & $266(8), 237(34)$ \\
& $298(39)$ & $267(24)$ & - & $241(3)$ & $249(32)$ & $223(16)$ & - & $58(100) 237(18), 221(5)$ \\
\hline
\end{tabular}

one at $\mathrm{m} / \mathrm{z} 239$ not occurring in other MS systems. Accurate mass determinations reveal that the fragment $\mathbf{b}$ has the formula $\left[\mathrm{C}_{14} \mathrm{H}_{12} \mathrm{O}_{2}\right]^{+}$, c corresponds to $\left[\mathrm{C}_{13} \mathrm{H}_{13} \mathrm{O}_{2}\right]^{+}$, e $\left[\mathrm{C}_{13} \mathrm{H}_{11} \mathrm{O}\right]^{+}$, and $\left(\mathbf{e}-\mathrm{H}_{2} \mathrm{O}\right)$ $\left[\mathrm{C}_{13} \mathrm{H}_{9}\right]^{+}$, respectively. The deviation from theoretical masses was approximately $5 \mathrm{ppm}$ for the Q-Tof and $<3 \mathrm{ppm}$ for the FT-ICR-MS using the IRMPD.

\section{Morphinone, Codeinone, and Neopinone}

These compounds have a keto group instead of hydroxy in position 6. Accordingly, MS/MS looks different (see Scheme 2 and Table 2). Ions of type a represent the base peak in the ion trap $\mathrm{MS}^{2}$ of morphinone $(\mathrm{m} / \mathrm{z} 227)$, codeinone and neopinone $(\mathrm{m} / \mathrm{z}$ 241). Moreover, the b-type fragments at $\mathrm{m} / \mathrm{z} 209$ (morphinone) and 223 (codeinone, neopinone) also show the corresponding mass shift compared with their non-oxidized analogues. On the other hand, there is only a weak signal at $\mathrm{m} / \mathrm{z} 213$ (ion c). Neopinone differs from codeinone just in the position of a double bond. Their fragmentation is similar, but the intensity pattern allows to distinguish between both isomers. The same is true for the MS/MS data obtained from the triple quadrupole instrument. The spectra of codeinone and neopinone only differs in their relative abundances, but a distinction of these two morphinans is possible (Table 2). The tandem mass spectra of morphinone are very similar to codeinone (mass shift by $14 \mathrm{u}$ ). The comparison of morphinone and morphine reveals a similar relationship as discussed above for codeinone and codeine also displaying the corresponding mass shifts by $14 \mathrm{u}$ (Tables 1 and 2). Although the main fragment peaks occur both in ion trap as well as in triple quadrupole MS/MS, the spectra look remarkably different (Table 2). The peak referring to $[\mathrm{M}+\mathrm{H}$ $\left.-\mathrm{CH}_{3} \mathrm{NH}_{2}\right]^{+}$is only detected in ion trap tandem MS. Fragment a represents the base peak in ion trap MS/MS, whereas it is outperformed in triple quadrupole MS/MS by the $(\mathbf{a}-2 \mathrm{H})$ ion. The ions of type $\mathbf{b}$, $\mathbf{c}, \mathbf{d}$, and $\mathbf{e}$ are observed in both types of spectra. In agreement with morphine and codeine the fragments $\mathbf{f}$ and $\mathbf{g}$ represent prominent key ions in the triple quadrupole MS/MS.

\section{Thebaine and Oripavine}

Thebaine and oripavine are closely related substances, only differing in one methyl at the 3-Oposition $(\Delta \mathrm{m}=14)$. The presence of two double bonds in ring $\mathrm{C}$ implies a completely different and more simple fragmentation compared to morphine and related analogues (Table 3). Besides the loss of methylamine generating the ion at $[\mathrm{M}+\mathrm{H}-31]^{+}$for thebaine at $\mathrm{m} / \mathrm{z} 281$ and oripavine at $\mathrm{m} / \mathrm{z} 267$ (base peak in ion trap $\mathrm{MS}^{2}$ ), respectively, only the $\mathrm{f}$ type ion at $m / z 58$ (base peak in the CID mass spectra of the TSQ) is prominent. The a fragments are relatively weak. Only in case of thebaine $(\mathbf{a}-\mathrm{MeOH})$ is detected, which has to be related consequently to the methoxy group in position 3. On the contrary, $m / z 249$ is found for thebaine and oripavine. It is assumed to be derived from $[\mathrm{M}+\mathrm{H}-31]^{+}$by a loss of water or methanol.

\section{Salutaridine and Salutaridinol}

Salutaridine and salutaridinol differ from the morphine type since the 4,5-epoxy bridge is opened and an additional oxygen is present in position 7 . The primary fragmentation of salutaridine is characterized by loss of methylamine $(\Delta \mathrm{m}=31)$ from the $[\mathrm{M}+$ $\mathrm{H}^{+}$ion (Table 4, Scheme 3). Both in the ion trap $\mathrm{MS}^{2}$ and the CID mass spectra of the triple quadrupole MS subsequent losses of $\mathrm{MeOH}$ lead to ions of type $\mathbf{i}(\mathrm{m} / \mathrm{z}$ $265)$ and $(\mathbf{i}-\mathrm{MeOH})$ at $m / z$ 233. An ion of the type [M $+\mathrm{H}-43]^{+}$appears only in ion trap MS/MS. The fragment at $\mathrm{m} / \mathrm{z} 298$ is formed by a loss of formaldehyde (salutaridine) and methanol (salutaridinol), respectively. The $[\mathrm{M}+\mathrm{H}-31]^{+}$fragment is generated by the loss of methylamine. Ion trap $\mathrm{MS}^{3}$ of this leads to the i-type fragments ([M $+\mathrm{H}-31-$ $\mathrm{MeOH}]^{+}$) which can cleave consecutively $\mathrm{CO}$ and $\mathrm{MeOH}$. The fragment $[\mathrm{M}+\mathrm{H}-43]^{+}$is found with a higher intensity as for thebaine or oripavine. These are thought to be formed by loss of N-methylformimine. Fragments a are relatively weak, except from $\mathrm{m} / \mathrm{z} 287$ for salutaridinol in ion trap MS/MS. In this case an ion of type (a-2H) was also observed. Nevertheless, the a fragments play a key role in the fragmentation pathway. Loss of methanol leads to 
Table 4. Key ions in the MS/MS spectra of salutaridine and salutaridinol. The first row indicates the ions found in the ion trap MS/MS, relative intensity $(\%)$

\begin{tabular}{|c|c|c|c|c|c|c|c|c|}
\hline Compound & {$[\mathrm{M}+\mathrm{H}]^{+}$} & {$[\mathrm{M}+\mathrm{H}-31]^{+}$} & {$[\mathrm{M}+\mathrm{H}-43]^{+}$} & a & $\mathrm{i}$ & $\left(\mathrm{a}-\mathrm{H}_{2} \mathrm{O}\right)$ & j & $(\mathrm{i}-\mathrm{CO})$ \\
\hline \multirow[t]{2}{*}{ Salutaridine } & 328 & $297(73)$ & $285(23)$ & $271(6)$ & $265(100)$ & $253(4)$ & $239(22)$ & $237(11)$ \\
\hline & $328(37)$ & 297 (11) & $285(19)$ & - & $265(35)$ & $253(-)$ & $239(41)$ & $237(100)$ \\
\hline \multirow[t]{2}{*}{ Salutaridinol } & 330 & $299(11)$ & $287(13)$ & $273(27)$ & $267(20)$ & $255(50)$ & $241(100)$ & $239(54)$ \\
\hline & $330(66)$ & - & - & - & $267(8)$ & $255(12)$ & 241 (77) & 239 (91) \\
\hline
\end{tabular}

the $\mathbf{j}$ fragments, which can split off either carbon monoxide or methanol or both neutrals. A parallel way leads from $(\mathbf{a}-2 \mathrm{H})$ to $(\mathrm{j}-2 \mathrm{H})$. The absence of the epoxy bridge facilitates the formation of an isoquinoline fragment at $\mathrm{m} / \mathrm{z} 192(\mathbf{k})$. This type of ion also represents a key ion in the EI mass spectra of morphinan-type alkaloids [21, 23]. An interesting ion at $m / z 242$ was observed in triple quadrupole MS /MS having the formula $\mathrm{C}_{15} \mathrm{H}_{16} \mathrm{NO}_{2}$, as determined by FT-ICR-IRMPD mass spectrometry. This ion probably originates from loss of ring C. Although most ions were detected both in ion trap as well as in triple quad tandem MS, the intensity pattern was different.

\section{Salutaridinol-7-O-Acetate}

Although this compound is closely related to salutaridinol, it needs to be discussed separately. The favored loss of acetic acid $(\Delta \mathrm{m}=60)$, resulting in the MS/MS base peak at $m / z 312$, leads the fragmentation into a different direction. Besides the $[\mathrm{M}-\mathrm{AcOH}]^{+}$ion a number of less intense ions are found in ion trap MS/MS: $m / z$ 281, 269, 255, 249, and 221. The ions appearing both in $\mathrm{MS}^{2}$ of the ion trap and the CID-MS of the TSQ are partly similar to those in the corresponding mass spectra of thebaine (Table 3). The elemental composition of the ions at $\mathrm{m} / \mathrm{z} 249$ $\left(\mathrm{C}_{17} \mathrm{H}_{13} \mathrm{O}_{2}\right)$ and $221\left(\mathrm{C}_{16} \mathrm{H}_{13} \mathrm{O}\right)$ in salutaridinol-7-Oacetate could be established by accurate mass determinations. The triple quadrupole product ion spectrum of salutaridinol-7-O-acetate is very similar to ion trap MS/MS. However, the intensity pattern is shifted towards smaller $\mathrm{m} / \mathrm{z}$ as commonly observed.

\section{Conclusion}

The study showed that electrospray tandem mass spectrometry is a powerful tool in the analysis of morphinan type alkaloids. In particular, both ion trap and triple quadrupole MS/MS provide information about the substitution at the morphinan skeleton (methoxy, hydroxy and oxo functions) and the position of the double bond(s) at the ring C. Especially, number and positions of the double bonds strongly influence the fragmentation behavior of the $[\mathrm{M}+\mathrm{H}]^{+}$ ion. This is shown in case of the morphinans with two conjugated double bonds at ring $\mathrm{C}$ (thebaine, oripavine) whose fragmentation behavior differs remarkably from those of the other morphinans. The influence of the double bond position is shown for the 6-oxomorphinans (morphinone, codeinone, neopinone). Although these three compounds show a similar fragmentation pattern, the relative abundances of some key ions allow a distinction between those possessing a 7,8-double bond (morphinone and codeinone) and the 8,14-double bond (neopinone). Fragment ions representing the isoquinoline moiety appear only in MS/MS of morphinans without the epoxy bridge (salutaridine, salutaridinol). Tandem MS with accurate mass measurements helps to elucidate the structure of important key ions, and ion trap $\mathrm{MS}^{\mathrm{n}}$ gives evidence to the postulated fragmentation pathways. Comparison of ion trap and triple quadrupole MS/MS reveals that the majority of fragment ions is common, even though the intensity pattern is clearly different. In general, the softer conditions of ion trap MS/MS give rise to more high mass fragments, whereas a number of low mass fragments seen in triple quad MS/MS appear in ion trap spectra, if ever, only in $\mathrm{MS}^{3}$ or $\mathrm{MS}^{4}$. However, these limitations should not prevent the setup of useful ESI MS/MS libraries.

\section{Acknowledgments}

The authors thank the Deutsche Forschungsgemeinschaft (Bonn, Germany) for funding of this project. They also would like to acknowledge Christine Kuhnt (Leibniz Institute of Plant Biochemistry, Halle) for skillful technical assistance.

\section{References}

1. Weinmann, W.; Svoboda, M. Fast Screening for Drugs of Abuse by Solid-Phase Extraction Combined with Flow-Injection Ionspray Tandem Mass Spectrometry. J. Anal. Toxicol. 1998, 22, 319-328.

2. Zheng, M.; McErlane, K. M.; Ong, M. C. High-Performance Liquid Chromatography-Mass Spectrometry-Mass Spectrometry Analysis of Morphine and Morphine Metabolites and Its Application to a Pharmacokinetic Study in Male SpragueDawley Rats. J. Pharm. Biomed. Anal. 1998, 16, 971-980.

3. Blanchet, M.; Bru, G.; Guerret, M.; Bromet-Petit, M.; Bromet, N. Routine Determination of Morphine, Morphine 3-D-Glucuronide, and Morphine 6-D-Glucuronide in Human Serum by Liquid Chromatography Coupled to Electrospray Mass Spectrometry. J. Chromatogr. A 1999, 854, 93-108. 
the second row shows those obtained from a triple quadrupole MS/MS (30 eV CID spectra). The values in brackets give the

\begin{tabular}{lcccccccc}
\hline & & & $(\mathrm{j}-$ & & $(\mathrm{j}-\mathrm{CO}-$ \\
$\mathrm{i}-\mathrm{MeOH})$ & $\left(\mathrm{a}-\mathrm{H}_{2} \mathrm{O}-\mathrm{MeOH}\right)$ & $(\mathrm{j}-\mathrm{CO})$ & $\mathrm{MeOH})$ & $\mathrm{k}$ & $\mathrm{MeOH})$ & $f$ & $\mathrm{~g}$ & Other \\
\hline \hline $233(4)$ & - & $211(3)$ & $207(2)$ & $192(16)$ & - & - & - & $298(10)$ \\
$233(18)$ & $221(9)$ & $211(45)$ & $207(39)$ & $192(13)$ & - & $58(50)$ & $44(14)$ & $270(34), 282(26), 255(22), 205(18), 183(15)$ \\
\hline $238(8)$ & $223(40)$ & $213(56)$ & $209(28)$ & $192(32)$ & $181(13)$ & & - & $298(15), 280(7), 273(27), 181(13)$ \\
$235(18)$ & $223(37)$ & $213(74)$ & $209(67)$ & $192(15)$ & $181(100)$ & $58(83)$ & $44(39)$ & $298(7), 242(88), 207(65)$ \\
\hline
\end{tabular}

4. Naidong, W.; Lee, J. W.; Jiang, X.; Wehling, M.; Hulse, J. D.; Lin, P. P. Simultaneous Assay of Morphine, Morphine-3Glucuronide, and Morphine-6-Glucuronide in Human Plasma Using Normal-Phase Liquid Chromatography-Tandem Mass Spectrometry with a Silica Column and an Aqueous Organic Mobile Phase. J. Chromatogr. B 1999, 735, 255-269.

5. Schanzle, G.; Li, S.; Mikus, G.; Hofmann, U. Rapid, Highly Sensitive Method for the Determination of Morphine and Its Metabolites in Body Fluids by Liquid Chromatography-Mass Spectrometry. J. Chromatogr. B 1999, 721, 55-65.

6. Slawson, M. H.; Crouch, D. J.; Andrenyak, D. M.; Rollins, D. E.; Lu, J. K.; Bailey, P. L. Determination of Morphine, Morphine-3-Glucuronide, and Morphine-6-Glucuronide in Plasma After Intravenous and Intrathecal Morphine Administration Using HPLC with Electrospray Ionization and Tandem Mass Spectrometry. J. Anal. Toxicol. 1999, 23, 468-473.

7. Cailleux, A.; Le Bouil, A.; Auger, B.; Bonsergent, G.; Turcant, A.; Allain, P. Determination of Opiates and Cocaine and Its Metabolites in Biological Fluids by High Performance Liquid Chromatography with Electrospray Tandem Mass Spectrometry. J. Anal. Toxicol. 1999, 23, 620-624.

8. Curcuruto, O.; Zaramella, A.; Hamdan, M.; Turrina, S.; Tagliaro, F. Capillary Zone Electrophoresis/Electrospray Ionization Mass Spectrometry for the Characterization of Drugs of Forensic Interest. Rapid Commun. Mass Spectrom. 1995, 9, 1487-1491.

9. Tsai, J. L.; Wu, W.-S.; Lee, H.-H. Qualitative Determination of Urinary Morphine by Capillary Zone Electrophoresis and Ion Trap Mass Spectrometry. Electrophoresis 2000, 21, 1580-1586.

10. Marquet, P.; Lachatre, G. Liquid Chromatography-Mass Spectrometry: Potential in Forensic and Clinical Toxicology. J. Chromatogr. B 1999, 733, 93-118.
11. Bogusz, M. J. Liquid Chromatography-Mass Spectrometry as a Routine Method in Forensic Sciences: A Proof of Maturity. J. Chromatogr. B 2000, 748, 3-19.

12. Baumann, C.; Cintora, M. A.; Eichler, M.; Lifante, E.; Cooke, M.; Przyborowska, A.; Halket, J. M. A Library of Atmospheric Pressure Ionization Daughter Ion Mass Spectra Based on Wideband Excitation in an Ion Trap Mass Spectrometer. Rapid Commun. Mass Spectrom. 2000, 14, 349-356.

13. Weinmann, W.; Gergov, M.; Goerner, M. MS/MS-Libraries with Triple Quadrupole-Tandem Mass Spectrometers for Drug Identification and Drug Screening. Analysis 2000, 28, 934-941.

14. Lips, A. G. A. M.; Lameijer, W.; Fokkens, R. H.; Nibbering, N. M. M. Methodology for the Development of a Drug Library Based Upon Collision-Induced Fragmentation for the Identification of Toxicologically Relevant Drugs in Plasma Samples. J. Chromatogr. B 2001, 759, 191-207.

15. Audier, H.; Fetizon, M.; Ginsburg, D.; Mandelbaum, A.; Rubl, T. Mass Spectrometry of the Morphine Alkaloids. Tetrahedron Lett. 1965, 1, 13-22.

16. Wheeler, D. M. S.; Kinstle, T. H.; Rinehart, K. L. Mass Spectral Studies of Alkaloids Related to Morphine. J. Am. Chem. Soc. 1967, 89, 4494-4501.

17. Hesse, M.; Bernhard, H. O. Progress in Mass Spectrometry/ Fortschritte in der Massenspektrometrie, Vol. III. Alkaloide. außer Indol-, Triterpen- und Steroidalkaloide. Verlag Chemie GmbH: Weinheim, 1975; pp 148-157.

18. De Hoffmann, E. Tandem Mass Spectrometry: A Primer. J. Mass Spectrom. 1996, 31, 129-137.

19. McLafferty, F. W.; Bente, P. F., III; Kornfeld, R.; Tsai, S.-C.; Howe, I. Metastable Ion characteristics. XXII. Collisional Activation Spectra of Organic Ions. J. Am. Chem. Soc. 1973, 95, $2120-2129$. 